\title{
Design of methodology for wood chips moisture estimation determined for gasification
}

\author{
Ladislav Lukáč $^{1, a}$, Štefan Kuna ${ }^{2}$, Ján Kizek ${ }^{1}$ and Magdaléna Repášová ${ }^{1}$ \\ ${ }^{1}$ Technical university of Kosice, Faculty of Metallurgy, Department of Furnaces and Thermal Technology, Letná 9/A, \\ 04200 Košice, Slovakia \\ ${ }^{2}$ Faculty of Manufacturing Technologies of the Technical University of Košice with a seat in Prešov, Štúrova 31,08001 \\ Prešov, Slovakia
}

\begin{abstract}
The moisture content of the charged wood chips is a significant factor affecting the gasification process. The increased moisture content increases the demand on the energy consumption, which is needed to cover the heat consumption related to the water evaporation and adversely affects the wood gas quality and input fuel amount. Monitoring of the moisture content in wood chips is therefore the diagnostic tools suitable to evaluate the operational parameters of the whole gasification process. Present paper describes the design of the suitable methodology to measure and estimate the wood chips moisture content. The issues related to the moisture content estimation include preliminary the selection of the suitable methodology based on the assumed moisture content in the wood chips. Further factor which needs to be considered is the fact that the moisture content in wood chips is time dependent due to the changing parameters of the ambient air (as temperature, pressure and air humidity). Correctly estimated moisture content will enable to improve the wood chips gasification process.
\end{abstract}

\section{Introduction}

Wood chips are the product of the cutting or other form of wood processing into the approximately equal fraction with or without the certain proportion of additives and bark. Due to its quality they are suitable for the use in the energy production. This is affected up to the certain level by the physical and chemical characteristics of the wood chips. This type of biomass is characterised by rather high and alternating moisture content which essentially affects the energy properties of fuel. Therefore the moisture content in the wood chips is important parameter. There are three mechanisms deciding about the water mode bound in the wood structure:

- Water bound by the chemical bonds in the molecular structure of wood - crystalline water,

- Physical absorption, due to which water is bound on the inner surface of the wood,

- Free water, which is located in the capillaries of the wooden matter.

Moisture content in the fuel significantly affects the fuel calorific value; it means that with the raising fuel moisture in the fuel its calorific value drops. That consequently means the increased fuel consumption to produce the same amount of energy in course of its

\footnotetext{
a Corresponding author: ladislav.lukac@tuke.sk
}

combustion, or increased energy consumption for water evaporation. Another disadvantage is that due to the increased moisture there is also increase in waste gas volume and adiabatic temperature of flame drops. Moisture content in the charge is one of the most important parameters affecting also the wooden mass gasification. High moisture content causes the loss of fuel in the same way as it is during combustion. This loss covers the heat needed for the fuel drying. Another problem accompanying the rise in fuel consumption with fuel of high moisture content is increased rise in tar production, prevailingly in counter-current gasification process. This points to the need to know the moisture content in the fuel - biomass. To be able to determine exactly the moisture content, it is necessary to select the suitable measuring method $[1,2,3]$.

In frame of the experimental verification at the Faculty of Manufacturing Technologies of the Technical University of Košice with a seat in Prešov, applied were two methods when the moisture content is determined after water separation from the solid phase. During the drying procedure water leaves the sample in form of vapour. Initial conditions of the drying media - air (its temperature and moisture content) and the absorption 
potential of water are decisive for the drying process [2, 4].

\section{The first drying method exploiting the oven}

This method is the most precise method of the moisture content in wood determination, and holds as the reference method for the moisture content in the solid fuels determination Based on the drying method in the oven the accuracy of other method is assessed. The moisture content in the wood matter is expressed in the field of energy in form of the relative humidity [5]. This method is based on the definition formula of the measured weight of water contained in the wood chips in relation to the weight of the wet chips according to the equation $[5,6]$ :

$$
M_{a r}=\frac{\left(m_{2}-m_{3}\right)-\left(m_{4}-m_{5}\right)+m_{6}}{\left(m_{2}-m_{1}\right)+m_{6}} \cdot 100(\%)
$$

where

$m_{l}$ - weight of empty crucible $(\mathrm{g})$;

$m_{2}$ - weight of crucible and sample before drying $(\mathrm{g})$;

$m_{3}$ - weight of crucible and sample after drying $(\mathrm{g})$;

$m_{4}$ - weight of the reference crucible before drying $(\mathrm{g})$;

$m_{5}$ - weight of the reference crucible after drying $(\mathrm{g})$;

$m_{6}$ - weight of the residual moisture in the cover of the sample $(\mathrm{g})$;

$M_{a r}$ - content of moisture in the biofuel (\%).

With the objective to avoid the essential misunderstandings, it is always necessary to know how is exactly expressed the moisture content in the considered wooden matter. In this experiment applied was the calculation of the moisture content as it is applied in the energy sector, i.e. calculation based on the formula (1). As the standard conditions, the European standards state the environment with the inside temperature of $20^{\circ} \mathrm{C} \pm 2^{\circ} \mathrm{C}$ and relative humidity of $65 \% \pm 5 \%$. The moisture content in wood will be set in such environment at the value of $12 \%$.

For the objective of the experiment, weighed were two sets of samples, each per 10 pieces of samples with approximately equal weight of $10 \mathrm{~g}$. Each sample was wrapped in the cover, into which added was small amount of water. The amount of added water was increased by $10 \%$ for each sample in sequence in both sets.

To determine the moisture content applying the drying method exploited were the following laboratory devices:

- Scales Metter Toledo ML104, with the weighing accuracy for the sample of $0,0001 \mathrm{~g}$,

- Facility for wood drying Binder, with the free circulation of the inside air and ability to maintain the temperature of $105^{\circ} \mathrm{C} \pm 2^{\circ} \mathrm{C}$.

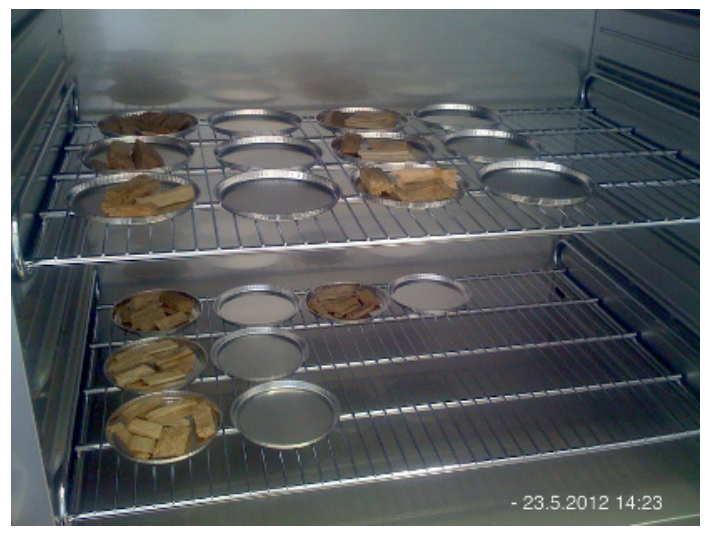

Figure 1. Reference crucible and crucible with the sample placed in the oven.

Each sample of the first set (10pcs) of the wood chips was uniformly distributed on the crucible made of stainless steel and thermally resistant (Figure1). Samples were weighed together with the empty (reference) crucible before the drying and the they were inserted into the oven, where they were dried under the temperature of $105^{\circ} \mathrm{C} \pm 2^{\circ} \mathrm{C}$, until the difference of the weight of the weighing executed in sequence within the interval of 1 hours was not less than $0,2 \%$. Each sample is to be weighed up to $15 \mathrm{~s}$, as immediately after taking it out from the oven, the hygroscope property of this fuel begins to act. Based on the obtained results calculated was the relative moisture content of each sample of the wood chips according to formula (1). The results from the measured and calculated values are given in Figure 2 [5].

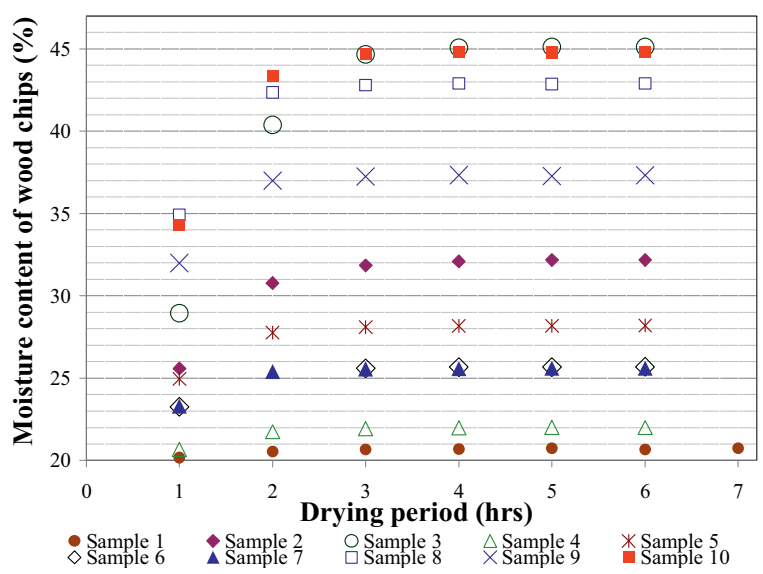

Figure 2. Results of the measured and calculated values exploiting the method of sample drying in the oven, where K1 constant weight of sample 1 .

\section{The second drying method exploiting the humidity analyser HR83}

Moisture content measurement of the second set of wood chips $(10$ pcs $)$ was realised exploiting the halogen analyser of humidity HR83 (Figure 3), operating on the thermo - gravimetric principle. 


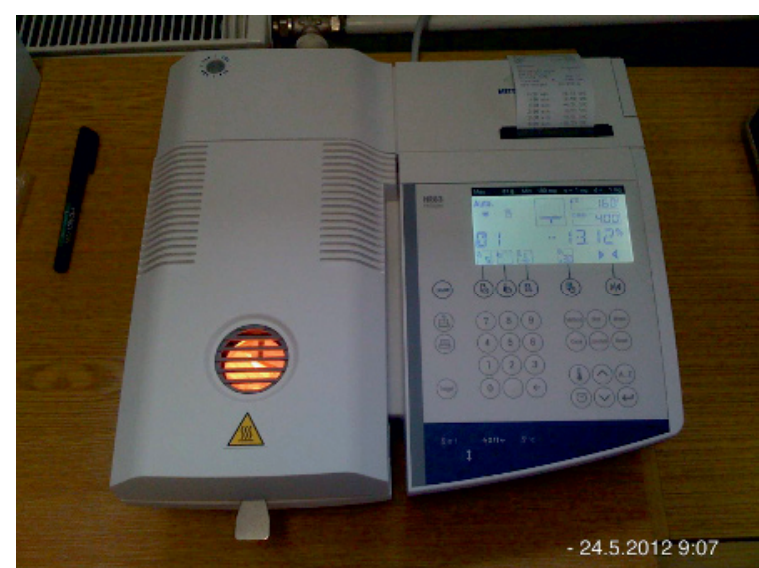

Figure 3. Halogen analyser of moisture content HR83.

After commencing the drying program, adjusted temperature of $160^{\circ} \mathrm{C}$ was exceeded by $40 \%$ during 3 minutes and thereby was the process significantly accelerated. As the device may achieve the maximum temperature of $200^{\circ} \mathrm{C}$, the process is maintained at this value and after passing 3 minutes the temperature will again decrease to the requested value, at which it is permanently kept until the drying process terminates.

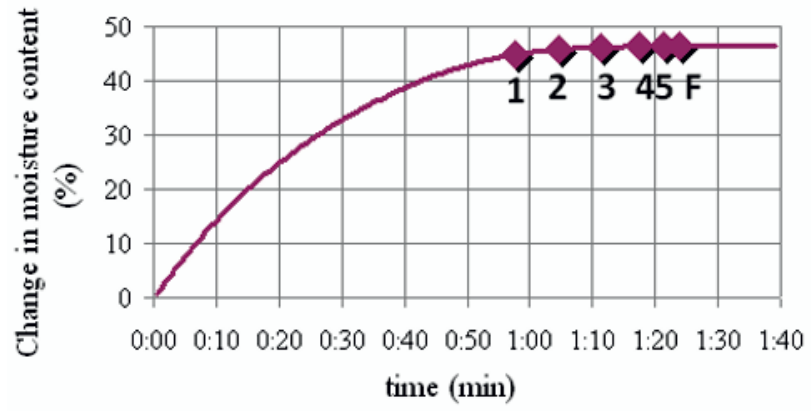

Figure 4. Change in moisture content with time.

Next, the criterion for the switching off was set to terminate the drying process. As the behaviour of the sample is not known, executed was the testing measurement to determine the application of the suitable criteria to terminate the process of the wood chips testing. As the testing criteria applied was the criteria of ,the weight drop per time unit", that assisted to set the suitable switching off criteria. Figure 4 provides the graph of the course of drying, where achieved were the individual switching off criteria $1-5$ and proposed selected criteria F. Based on the achieved values, with the objective to increase the accuracy of the wood chips moisture content measurement, as most suitable seems to be the switching off criteria No. 5 .

After the adjustment the option for the presentation type and frequency of the measured values printing, the empty crucible was placed into the device to reset the device. After the resetting, the sample of $10 \mathrm{~g}$ of the wood chips was uniformly distributed on the crucible. At the beginning of the measurement the analyser determines the exact weight of the sample before the drying and then follows the heating up of the sample of wood chips to the required temperature, when the moisture is evaporated.
Heating is realised with the help of the built in halogen heating module.

In course of the drying process, the instrument permanently determines the weight of the sample and provides the data on the drop in moisture. The drying process is terminated automatically, when the mean value of the weight drop per time unit is lower than pre-set value, based on the selected switching off criteria. The instrument calculates the drop in the moisture content according to the formula:

$$
M_{C}=-\frac{w_{w}-d_{w}}{w_{w}} \cdot 100(\%)
$$

where

$w_{w}$ - initial weight $(\%)$

$d_{w}$ - dry mater content $(\%)$;

$M_{c}$ - loss of moisture content (\%).

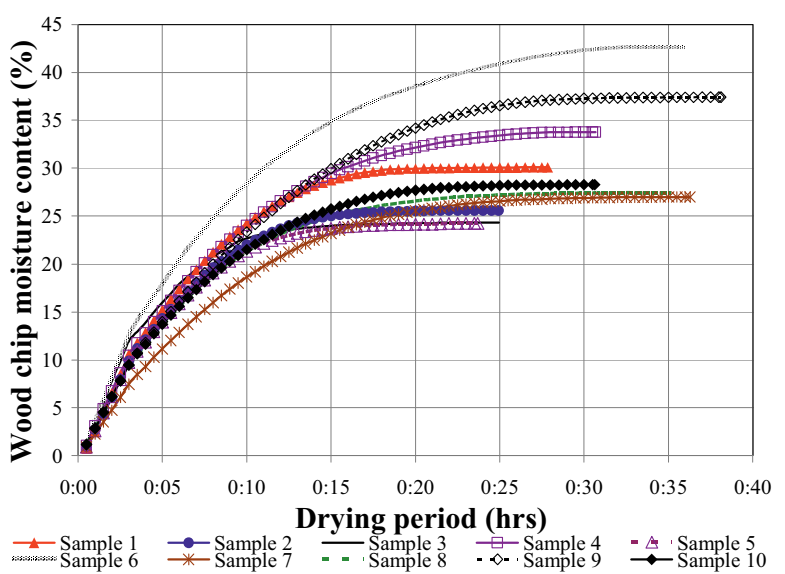

Figure 5. Results from measurements on the halogen analyser HR83.

After the drying termination, the final result is expressed in the form of the relative moisture content drop, period of drying and final weight of the sample. Figure 5 presents the graph for all samples as their change in drop of moisture with time.

\section{Effect of moisture content on wood chips gasification}

Gasification is the conversion of biomass to a gaseous fuel by heating in a gasification medium such as air, oxygen or steam. Unlike combustion where oxidation is complete in one process, gasification converts the intrinsic chemical energy of the carbon in wood into a combustible gas. The gas produced is easier and more versatile to use than the solid biomass e.g. it be used to power gas engines.

A small-scale updraft (counter-flow) gasifier has been installed in Department of Furnaces and Thermal Technology to provide wood-gas for heat and power production (CHP). A decision to build the updraft fixed bed gasifier consists in its simplicity. The major limitation for the updraft gasifier is a high concentration of tar in the wood gas that requires extensive cleanup. The wood-gas is therefore very difficult to utilise without 
removing tars. Generally it has been proven and explained scientifically and technically that updraft gasifier produces more "tar" than fluidised beds and more than downdraft gasifier too.

The project has an integration of an internal combustion (ICE) engine to operate on a wood gas produced by the up-draft gasifier. However, for the ICE application it is necessary to implement primary and secondary methods to radically reduce tar concentration in the cooled wood-gas fuelling the ICE engine [7].

Moisture content in the feedstock is one of the most important parameters influencing the gasification of the wood biomass. High moisture causes losses of fuel involved to cover the heat required for drying of the fuel. The analysis confirmed that, high fuel moisture content increases the fuel consumption, decreases excess of air for gasification, and also the specific consumption of the gasification air.

It is necessary to further study the dependence of fuel moisture and to find the optimal moisture limits for its use in the gasification technology. Premise is that for different moisture contents and different fuel types optimal will be also the different excess of air for gasification, not least influencing the composition, calorific value, the amount of produced gas and the efficiency of the process and intended use of the product gas [8].

\section{Conclusions}

In spite of the fact that the drying in the oven is the reference method, it is essentially more time consuming than the compared method exploiting the analyser of humidity HR83. Due to its demands related to the preparation and duration of the measurement, the method of drying in the oven is not suitable method in case of need of the speedy and accurate estimation of the moisture content of wood chips. It also does not provide the actual presentation of the moisture content drop of wood chips and due to the manual procedure, it is not terminated automatically. The method of drying in the oven is the suitable method in case of need of the great accuracy estimation of wood chips moisture content. The calculation according to the formula (2), based on which the halogen analyser determines the moisture content of the wood chips, on the contrary to the previous method, does not include the weight of the moisture in connection with the cover, in which was the sample wrapped. This may be the cause of small differences in results of the calculations. The advantage of the drying method in the halogen analyser is, in spite of the above mentioned inaccuracy, essentially shorter time of the moisture estimation and it is by $24-40$ minutes. In the case of the sample drying in the over, the correct values were achieved only after 3 - 5 hours, as it is demonstrated in graph in Figure 2. Analyser provides the possibility to observe the actual drop of moisture of the wood chips (Figure 5) and automatic termination of the drying process. Another advantage of the method of drying in the halogen analyser is essentially lower severity related to the preparation and overall course of the moisture estimation. It is more suitable method in case when there is request of the high accuracy of the results of the moisture content measurement in the wood chips.

The moisture content of the charged wood chips is a significant factor affecting the gasification process. The increased moisture content increases the demand on the energy consumption, which is needed to cover the heat consumption related to the water evaporation and adversely affects the wood gas quality and input fuel amount. Monitoring of the moisture content in wood chips is therefore the diagnostic tools suitable to evaluate the operational parameters of the whole gasification process.

\section{Acknowledgement}

This article is the result of the Project implementation: Research Centre for efficient integration of the renewable energy sources, ITMS: 26220220064 supported by the Research \& Development Operational Programme funded by the ERDF.

\section{References}

1. J. Jandačka, M. Malcho, M. Mikulík, Biomasa ako zdroj energie, 241 (2007)

2. M. Trenčiansky, M. Lieskovský, M. Oravec, Energetické zhodnotenie biomasy, 147 (2007)

3. A. Varga, J. Kizek, T. Suchý, et al., Research and Development Projects, 80 (2007)

4. M. Baláš, J. Moskalík, Energie z biomasy X, 9 (2009)

5. STN EN 14774-1, (2010)

6. STN EN 13183-1, (2003)

7. D. Holoubek, L. Lukáč, Energy transformations in industry: 13th International scientific conference, 44 (2013)

8. L. Lukáč, G. Jablonský, S. Kočanová, F. Furka, 32. stretnutie katedier mechaniky tekutín a termomechaniky, 169 (2013)

9. Z. Pastorek, J. Kára, P. Jevič, Biomasa-obnovitelný zdroj energie, 288 (2004)

10. S. Pang, Q. Xu, Mathematical modeling and optimization, 28, 702 (2010)

11. T. Yoshida, H. Sasaki, T. Takano, O. Sawabe, Biomass and Bioenergy, 34, 1053 (2010)

12. D. Košičanová, P. Kapalo, Czasopismo Techniczne, 109, 247 (2012)

13. D. Košičanová, P. Kapalo, SGEM 2012 : 12th International Multidisciplinary Scientific GeoConference : conference proceedings, 4, 611 (2012)

14. P. Lukáč, P. Horbaj, Plynár-Vodár-Kúrenár, 2, 12 (2007)

15. P. Lukáč, P. Horbaj, Plynár-Vodár-Kúrenár, 3, 76 (2007) 